\title{
Ten years of research and publications about hospice and palliative care in Mainland China: a bibliometric study
}

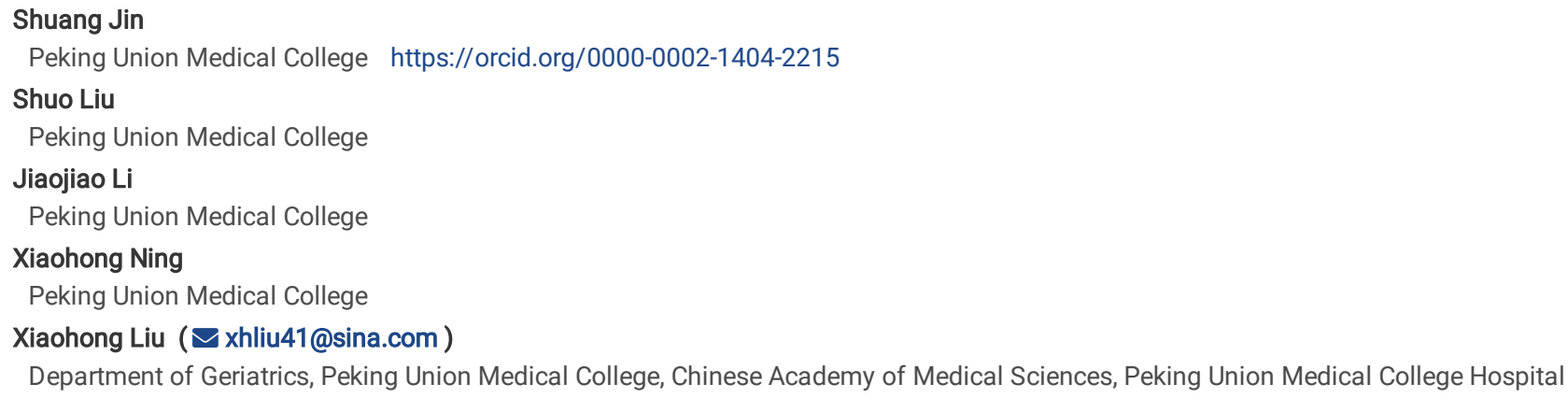




\section{Abstract}

Background Research is a fundamental element in the sustainable development of hospice and palliative care. Mainland China is facing increasing demand for hospice and palliative care and has launched related policies over the past decade. However, the state of research and publications in this field in China remains largely unknown. This study aimed to provide an overall picture of hospice-and palliative care -related research and publications in Mainland China from 2010 to 2019. Methods We searched Web of Science, Scopus, PubMed, CINAHL, OVID, and China National Knowledge Infrastructure for hospice-and palliative care -related publications in English and Chinese for 2010-2019. We analyzed the production, citations and impacts, publishing journals, region and institution of origin, and themes and active topics. Results A total of 3224 publications were identified, and 636 of them were considered of high quality. The production and impacts showed a clear increase-especially after 2016. However, the regional disparity between East and Western China in production was conspicuous and closely linked to economic factors. Beijing and Shanghai were the most productive regions. The hospice providers in the first five pilot regions had no collaboration with leading universities in their publications. Hospice and palliative care for cancer patients was the most common publication topic; some essential themes were rarely explored. Conclusion Research and publications of hospice and palliative care in Mainland China is developing faster than before; however, it remains at an early stage and should be promoted in terms of interregional equity. Collaboration among different disciplines, institutes, and regions should be encouraged.

\section{Background}

Hospice and palliative care (HPC) is a fundamental human right and a crucial part of an integrated, person-centered health service. The world as a whole has made rapid progress in this sector, but HPC in Mainland China has long been in a state of infancy [1]. According to the 2010 Quality of Death Index by the Economist Intelligence Unit, China ranked 37th among the 40 countries and regions [2]. Five years later, in 2015, the second edition of Quality of Death Index ranked China the 71 st among the 80 countries and regions, revealing limited progress [3].

Though HPC has developed slowly in Mainland China, the demand for it has undoubtedly increased. China has a rapidly aging population: in $2019,17,599$ million Chinese were aged over 65 years (12.6\% of the total population) [4]; that proportion is estimated to reach $26.9 \%$ in 2050 [5]. Meanwhile, chronic noncommunicable diseases (including stroke, ischemic heart disease, lung cancer, chronic obstructive pulmonary disease, and liver cancer) have become a major burden; they are the main causes of years of life lost [6]. According to the Serious Health-Related Suffering (SHS) Database in 2015, it was estimated that 10443 thousand people (7.55\% of the population) in China were in need of palliative care [7]. Meanwhile, futile medication at the end of life is still prevalent in China [8]. According to a recent study, aggressive care and catastrophic health expenditure are common for cancer patients and families. More than $80 \%$ of the families of cancer patients were left below the poverty line after the patients' death [9]. Most patients are willing to learn more about HPC, but few have access to it [10].

In light of this situation, the Chinese government has promoted related policies over the last decade. In 2012, Shanghai began promoting a community-based hospice service [11]. In 2014, China, along with the other 194 countries in the 67th World Health Assembly, committed to enhancing HPC as a component of comprehensive care throughout the life course [12]. In 2017, the former National Health and Family Planning Commission of China issued a guideline for hospice care [13]; subsequently, five regions were chosen for a national pilot on hospice implementation. In 2019, the number of pilot regions expanded to 71[14].

Though China's policy making has become active in this regard, there has been no adequate promotion of research. The role of research has been identified as a fundamental element for sustaining the development of HPC [15]. The lessons learned from previous research have shaped and fueled the implementation of HPC within the standards of evidence-based medicine [16]. Thus, the state of research and publications should be regarded as a key measure when examining the development of HPC in a region. Previous reports have identified a growth in HPC-related publications, both globally and in the Asia-Pacific region [17-19]. However, documents in Chinese were not included owing to the language barrier. Recently, investigators from Hong Kong managed to avoid the "Tower of Babel" bias by searching in Chinese: they found a considerable knowledge gap related to HPC research in Mainland China [20]. However, the authors focused on original studies with a strict inclusion criterion and failed to provide a whole picture of the structural changes in the HPC-related literature that have occurred over recent years.

In the present study, we sought to remedy that deficit by analyzing HPC-related publications from Mainland China from 2010 to 2019 , including both primary and secondary literature, in English and Chinese. Employing bibliometric tools, we investigated the production, regional distribution, impacts, and development related to this young discipline. We aimed to depict a panoramic, yet detailed, view of HPC-related research and publications in Mainland China: that is crucial to understanding the present situation and future direction for the sustainable development of HPC. We also hope that the study could provide beneficial information for promoting research in China and other low- and middle-income countries.

\section{Methods}

Data source and document retrieval 
In this study, we searched the Web of Science (WoS), Scopus, PubMed, CINAHL, and OVID for publications in English. The China National Knowledge Infrastructure (CNKI) was searched for ones in Chinese. CNKI is the largest digital publishing platform in China, and it covers a whole category of academic resources, including China's largest academic database, the Chinese Journal Full-Text Database (CJFD). We retrieved relevant articles published from January 2010 to December 2019 from the international databases if they contained "Chinese" or "China" in the affiliation address and contained any of the following terms in the title, abstract or keywords: "palliative care," "hospice," "end-of-life care," or "terminal care." The searching strategy is shown in the additional file. When searching for Chinese articles in CNKI, we applied various Chinese versions of "HPC" as follows: "huan-he-yi-liao," "shu-huan-yi-liao," "shu-huan-liao-hu," "gu-xi-yi-xue," "gu-xi-zhi-liao," "gu-xi-guan-huai," "an-ning-liao-hu," and "lin-zhong-guan-huai." All the above terms have appeared in Chinese literature at different times and in different regions. We restricted the literature types to consensuses, guidelines, editorials, original research, and case studies. To eliminate the possibility of duplication with original research, we excluded conference proceedings, master's theses, and doctoral dissertations. After completing the retrieval, we reviewed the titles, abstracts, and author affiliations of the documents according to the following exclusion criteria: (1) The topic is curative medicine. (2) The article was in English and focused on Taiwan, Hongkong, Macao, and other places outside Mainland China. (3) The article was a translation of work that had already appeared in an international journal. We did not exclude articles if they were in Chinese and described the situation of HPC in places other than Mainland China: such articles play an essential role in distributing knowledge and reflect people's interest. Two reviewers (S.J. and S.L.) independently screened the documents for exclusion. Conflicts were resolved by discussion and mutual agreement. The procedure is shown in figure 1.

\section{Figure 1: Flow chart of the bibliometric study}

To conduct an additional impact assessment and content analysis with a focused data source, we created a subgroup of high-quality publications. The quality of a specific article is very hard to determine. So, we used the quality of the publishing journal as a substitute for the quality of the article. If an article is published in a core journal according to the Peking University Library [21], or in a journal included in internationally recognized databases like WoS, Scopus, etc., it means that the article passed the rigorous peer review and can be considered as a high-quality article. The list of core journals of Peking University Library has been widely accepted in China for years. Searching for articles within core journals is a built-in function of CNKI. The core journal list is renewed periodically; thus, some journals may become newly included as their quality improve. We did not consider articles published in those journals before the inclusion year in the high-quality subgroup. The articles were assigned to a specific province or municipal city according to the affiliation address of the first author.

\section{Bibliometric indicators}

Several bibliometric indicators were used here to evaluate scientific activity in the field of HPC. Production indicates the ability to create knowledge in a given period. It was assessed using the number of publications as well as that number per million inhabitants. We obtained socioeconomic parameters, such as the number of inhabitants and regional gross domestic product (GDP), from the National Bureau of Statistics of China on April 26, 2020 [4]. To evaluate the pattern of growth, we conducted a linear adjustment and exponential adjustment.

The impacts indicate the quality of the articles published by a specific region. They were measured using the regional impact factor (RIF): that is similar to the impact factor of a journal and could be established each year based on the previous 2-year period. We determined the RIF of a given year as follows: the denominator signified the total number of articles published during the 2 years before the index year; the numerator signified the number of citations in the index year of the articles included in the denominator. Some regions produce few publications; thus, we introduced the 5-year RIF of 2019 as a more stable indicator for interregional comparison. The 5-year RIF was the same as the RIF, except it used a 5-year time window. To avoid excessive articles with no citations, the calculation of impact factors employed only the citation data of high-quality publications.

\section{Content analysis}

The articles in the high-quality subgroup were categorized according to literature types and themes. We regarded original research and case reports as primary literature and reviews, guidelines, and consensus studies as secondary literature. No editorial among our data followed an introduction-method-resultdiscussion format pattern, so we classified them as secondary literature. According to the subject and research theme described in the abstract, the two reviewers classified each article into the following categories with mutual agreement:

1. Aging and geriatric HPC

2. Pediatric HPC

3. HPC in cancer patients

4. HPC in non-cancer patients

5. Pain and symptom management

6. Rehabilitation and nutrition 
7. Spiritual and psychological care

8. Complementary therapy

9. Humanity and art

10. Communication and advanced care planning

11 . Family caregivers and volunteers

12. Bereavement

13. Self-care of the HPC team

14. Education and training

15. Nursing in HPC

16. HPC in primary care

17. HPC in other specialties

18. Ethics

19. Policy and program advocacy

20. Assessment of needs and implementation of HPC

21. HPC timing and screening

We adopted those categories following the advice of the Asia Pacific Hospice Palliative Care Network with some modifications [22]. Overlap was permitted, and so each article could fall into more than one category. There is an example of literature categorization in the additional file.

We analyzed the trend in research interests using CiteSpace $\$ (version 5.6.R3), a JAVA-based software that can detect the word bursts over a period of time [23]. A word burst is a surge in the frequency of the appearance of a word: it is a valuable indicator of active research topics [24]. Owing to language differences, we applied the burst detection to articles in English and Chinese separately.

\section{Statistics}

According to the finding of Derek John de Solla Price, scientific knowledge grows exponentially [25]. We applied a regression analysis to test if the growth of HPC-related publications fulfills Price's law, that is to say, follows a pattern of normal growth. The regression analysis was performed using IBM SPSS Statistics 26 . We conducted a linear adjustment of the total publications according to the equation $y=41.794 x-83871$ and an exponential adjustment according to the equation $y=4.562 \mathrm{E}-103 \mathrm{e}^{0.12 x}$. We undertook a similar analysis with the high-quality subgroup according to the following equations: $\mathrm{y}=11.188 \mathrm{x}-22474$ versus $\mathrm{y}=1.183 \mathrm{E}-151 \mathrm{e}^{0.175 x}$. Difference were considered significant at a $P$-value below 05 .

\section{Results}

\section{Growth of HPC-related publications}

We identified 3224 documents as HPC-related publications for 2010-2019; among them, 636 were high-quality publications and 255 were in English. Irrespective of quality, the annual number of publications grew notably during the 10-year period (Figure 2). According to the regression analysis of total publications, the $R^{2}$ was 0.873 when adjusted to an exponential curve; it was 0.784 with a linear adjustment. This finding indicates that exponential growth better explained the pattern of increase, thereby fulfilling Price's law[25]. A similar pattern was evident in the high-quality subgroup: the $R^{2}$ was 0.925 with an exponential adjustment and 0.830 with a linear adjustment. We also observed a sharp increase in total publications after 2016 . A similar, though milder, trend was evident in high-quality publications after 2017. The impacts of scientific production also rose during the study period.

\section{Figure 2: Annual development of production and impacts of publications}

\section{Joumals publishing HPC-related articles}

Table 1 shows the top 10 productive journals of total and high-quality publications. In the case of total publications, the articles were distributed among various journals: the 10 leading journals published only $18.7 \%$ of all publications. Only three of those 10 are core journals according to the latest criterion of Peking University Library. This scattering pattern was not manifest with the high-quality subgroup: the leading 10 journals accounted for $40.4 \%$ of articles. They act as a group of core publishers for high-quality HPC-related articles from Mainland China. There were three international journals on the list: Journal of Pain and Symptom Control, American Journal of Hospice and Palliative Medicine, and Supportive Care in Cancer. The other journals are all China-based. Notably, there is no specialized HPC journal in Mainland China. The listed journals are interconnected with HPC in the field, such as general practice and nursing, but not HPC-based journals themselves. 
Table 1: Top 10 journals publishing HPC-related articles

Note: ${ }^{1}$ The Chinese Core Journals. ${ }^{2}$ International Journals in English.

\section{Regional distribution of the publications}

Although the overall growth of HPC-related publications during the 10-year period appears promising, the regional disparity was substantial (Figure $3 \mathrm{~A}$ ). In decreasing order, the five most productive regions were Beijing (11.8\% of total production in Mainland China), Shanghai (11.1\%), Jiangsu ( $8.2 \%)$, Guangdong (7.3\%), and Sichuan (5.3\%). By contrast, China's northern and western provinces lacked publications. When adjusted by the number of inhabitants, the prominence of Beijing and Shanghai became greater: during the 10-year period, they contributed 17.6 and 14.8 articles per million inhabitants, respectively. They were followed at a considerable distance by Tianjin (5.5), the city with the first-ever hospice center in Mainland China (Table 2). There was a strong correlation between annual production and regional economy (Figure 3B). However, on that basis, Beijing and Shanghai were outliers and performed much better than could be expected. The regional difference in publication impacts is indicated by the 5-year RIF (Table 2); there was no clear correlation between productivity and impacts $\left(R^{2}=0.02, P=0.42\right)$.

The names and locations of the top 10 productive institutes appear in Figure 3A: they are all universities and colleges with affiliated hospitals. It is noteworthy that four of the 10 institutes were located in Beijing and Shanghai; only one (Sichuan University) was in Western China. We also examined the production of the 41 institutes that provided HPC in the first five pilot regions for hospice implementation. Those institutes published 51 articles and had no collaborations with the leading institutes listed in Figure 3.

\section{Figure 3: Regional distribution of publications}

Note: A, A heatmap of regional production, and locations and ranks of the top-10 productive institutes; $\mathrm{B}$, an example of the correlation between annual regional GDP and number of publications in 2019. The GDP was based on a currency exchange rate of 689.85 Chinese Yuan to 100 United States dollar in 2019. Beijing and Shanghai were excluded from the regression model as outliers. The heatmap was generated by Microsoft Excel. The map was adapted from Bing®GeoNames, HERE, MSFT, Microsoft, NavInfo, Wikipedia with permission from Microsoft Corporation.

\section{Table 2ПRegional indicators of production and impacts}

\section{Themes of the publications}

We further analyzed high-quality publications concerning their literature type and content. In this subgroup, 411 of 636 articles were original research and 10 were case reports; thus, primary literature accounted for $66 \%$ of the total. Secondary literature comprised of 212 reviews or editorials and three consensuses. The articles were further categorized according to their themes. As shown in Table 3, HPC in cancer patients was the leading topic; that was followed by pain and symptom management, assessment of needs and implementation of HPC, and policy and program advocacy. The topics that received minor attention were bereavement, HPC screening and timing, rehabilitation and nutrition, self-care of the HPC team, and pediatric HPC.

\section{Table 3: Themes in high-quality publications}

We examined trends in research interest in HPC with the word burst detection function of CiteSpace区. Figure 4 shows the key words that began to burst from 2015. For example, one Chinese version of HPC (shu-huan-liao-hu) burst between 2015 to 2017, appearing in 100 articles. The terms "negative emotions" and "pain management" constituted the frontier of interest in 2019 and may continue to receive future attention.

\section{Figure 4: Key words and burst periods from 2015}

Note: ${ }^{1}$ One Chinese version of HPC (shu-huan-liao-hu); ${ }^{2}$ original terms in English-language articles not translated

\section{Discussion}


In this study, we attempted to provide an overall assessment of research and publications related to HPC in Mainland China over a 10-year period. During that time, both the production and impacts of the publications increased; however, regional disparities were conspicuous. There was also a lack of a discussion of some important areas of HPC.

\section{Growing out of infancy}

The first hospice in Mainland China was founded in the municipal city of Tianjin in 1988[26]. But the adoption of HPC in Mainland China has been slow. Even among health professionals, there is still insufficient knowledge of the subject [27]. However, the present study found that the number of HPC-related publications in 2019 was almost three times that in 2010. The exponential rise of the production and impacts of HPC-related publications is a sign of academic attention and discussion, which are vital for professional education as well as research innovation. In our opinion, this trend will lead HPC in Mainland China out of its infancy.

There are several reasons for the growth. According to the 2010 and 2015 Quality of Death Index by the Economist Intelligence Unit, China is among the countries with the lowest rank [2, 3]. All three countries with a lower ranking than China in 2010 surpassed it in 2015 . This was widely covered by Chinese media and elicited broad discussion, stimulating health-care workers and policy makers to reexamine the medical system and service. At the same time, a series of new policies prompted the promotion of knowledge about HPC. For example, community care, which burst as a key word in 2015 , has been promoted by the government since 2012. The burst detection also showed a promising shift of key words from main concepts to practical issues, such as pain management and negative emotions, which may lead to more clinically relevant research.

Despite its growth, research into HPC in Mainland China remains at an early stage. First, the number of high-quality publications per million inhabitants is meager compared with other parts of Asia [19]. Second, a large number of those publications are secondary literature, which introduces ideas and knowledge but does not explore the unknown. Third, HPC for non-cancer patients is far less discussed than for cancer patients, and end-of-life care or hospice receives greater attention than integrated palliative care in an early stage. Thus, many professionals may be unaware of the latest concept of palliative care [28]. Fourth, there is still no specialized HPC journal in Mainland China. It hinders the development of the academic community of HPC professionals. Accordingly, policies should be designed to support original research, education, and publications in HPC.

\section{Conspicuous regional disparity}

Imbalanced development in China has long been recognized-especially between East and Western China [29]. This inequality is evident in many areas, including the economy, human capital, public facilities, and science and innovation. Studies have observed that economic factors are closely linked to a country's production of HPC-related publications [30]. We found that relationship also applies on a provincial scale. When residents in less prosperous regions have limited access to curative medicine [31], an insufficient HPC service will close the door to relief. Thus, the regional disparity in research and publications is both a result and a component of that imbalance, which would produce the Matthew effect and cause inequity in HPC.

China's great cultural richness warrants more research in different regions and populations. Chinese attitudes toward death are heterogeneous. One study among Christians in a northern rural region of China determined that $95 \%$ could freely talk about death at home; $85 \%$ felt joyful when thinking about death [32]. That finding is against the stereotype of Chinese people. Another study from urban areas showed that older people were more willing to die in hospital than younger ones [33]; that is also against the stereotype of the elderly. Owing to different cultural and social factors, patients' attitudes to HPC varied from hostility to embracing the approach [34,35]. Some regions with fewest publications (such as Tibet, Hainan, Xinjiang, and Inner Mongolia) are home to various ethnic groups. Thus, in a rapidly changing, culture-rich society, we believe that more research is needed to understand local needs and promote culturesensitive care.

\section{Call for collaboration}

The study identified a lack of collaboration at different levels. From the names of journals publishing HPC-related articles, nurses, general practitioners, and geriatricians are especially active in this field. However, researchers from other specialties, such as emergency medicine and intensive care, were scarce. Nurses have done excellent work in HPC research. However, in Mainland China, nurses are not allowed to prescribe medications, which compromises their ability to conduct intervention studies. More doctors from different specialties, nutritionists, physical therapists, psychologists, social workers, and other related professionals should be involved in multidisciplinary HPC research.

At the institutional level, the hospice providers in the first five pilot regions had no collaboration with leading universities in their publications. HPC is highly practical, so we strongly recommend collaboration between HPC providers and professional researchers. Future policies and funding should support this 
collaboration.

International collaboration is also important for HPC practitioners and researchers in Mainland China: they should seize opportunities to communicate with researchers from the rest of the world, especially other Asian regions. Overall, collaboration is the way to make more people heard.

\section{Strengths and limitations}

To our knowledge, this is the first study that provides a whole picture of HPC-related research and publications in Mainland China. Our study has several limitations. First, the terminology for HPC in Mandarin Chinese is not unified, and so we included various versions. We may have missed articles that did not mention those terms. Second, it was difficult to determine the actual quality of an article. We used the quality of the publishing journal as a substitute for the quality of the article. However, a high-quality article can be published in a non-core journal [36]. Third, some excellent HPC centers dedicated themselves to delivering care rather than research. Their efforts were largely invisible in our study. Future investigations should aim to determine the factors that hinder or promote research in HPC.

\section{Conclusion}

China is a good example of a low- and middle-income country with limited, yet highly demanded, implementation of HPC. The 10-year study period witnessed a considerable increase in HPC-related publications in Mainland China. However, regional disparity in production was conspicuous, and HPC research is at an early stage. Research is essential for the sustainable development of HPC and should be promoted with interregional equity. Policies should be made to encourage collaboration among different disciplines, institutes, and regions. Future research is needed to identify the factors that hinder or promote research in HPC.

\section{Abbreviations}

HPC: Hospice and palliative care

WoS: Web of Science

CNKI: China National Knowledge Infrastructure

RIF: Regional impact factor

GDP: Gross domestic product

\section{Declarations}

\section{Ethics approval and consent to participate}

Not applicable

\section{Consent for publication}

Not applicable

\section{Availability of data and materials}

The data analyzed during the current study are available from the corresponding authors on reasonable request.

\section{Competing interests}

The authors declare that they have no competing interests.

\section{Funding}

The work was supported by Irma and Paul Milstein Program for Senior Health of the Milstein Medical Asian American Partnership Foundation (No grant number was available). With this support we were able to pay for the editing fee. 


\section{Authors' contributions}

S.J., X.L., and X.N. developed the concept and design of the study. S.J. and S.L. collected the data and reviewed the publications. J.L. did the statistical analysis. J.S. wrote the manuscript. All authors read and approved the final manuscript.

\section{Acknowledgements}

We thank Liwen Bianji, Edanz Group China (www.liwenbianji.cn/ac), for helping us edit a draft of this manuscript.

\section{References}

1. Li JX, Davis MP, Gamier P: Palliative Medicine: Barriers and Developments in Mainland China. Current Oncology Reports 2011, 13(4):290-294.

2. The Economist Intelligence Unit. The quality of death, ranking end-of-life care across the world. 2010. Available from: https://palliumindia.org/2010/07/quality-of-death-ranking-end-of-life-care-across-the-world/. Accessed April 10, 2020.

3. The Economist Intelligence Unit. The 2015 Quality of Death Index, ranking palliative care across the world 2015. Available from: https://eiuperspectives.economist.com/healthcare/2015-quality-death-index-. Accessed April 10, 2020.

4. National Bureau of Statistics of China. Available from: http://www.stats.gov.cn/english/Statisticaldata/AnnualData/. Accessed April 26, 2020.

5. Fang EF, Scheibye-Knudsen M, Jahn HJ, Li J, Ling L, Guo H, Zhu X, Preedy V, Lu H, Bohr VA et al: A research agenda for aging in China in the 21st century. Ageing research reviews 2015, 24(Pt B):197-205.

6. Zhou M, Wang H, Zeng X, Yin P, Zhu J, Chen W, Li X, Wang L, Wang L, Liu Y et al: Mortality, morbidity, and risk factors in China and its provinces, 19902017: a systematic analysis for the Global Burden of Disease Study 2017. Lancet 2019, 394(10204):1145-1158.

7. Serious Health-Related Suffering (SHS) Database, 2015. Available from: https://hospicecare.com/what-we-do/resources/global-data-platform-tocalculate-shs-and-palliative-care-need/database/. Accessed August 20, 2020.

8. Sheng J, Zhang YX, He XB, Fang WF, Yang YP, Lin GN, Wu X, Li N, Zhang J, Zhai LZ et al: Chemotherapy Near the End of Life for Chinese Patients with Solid Malignancies. Oncologist 2017, 22(1):53-60.

9. Leng AL, Jing J, Nicholas S, Wang J: Catastrophic health expenditure of cancer patients at the end-of-life: a retrospective observational study in China. Bmc Palliative Care 2019, 18.

10. Yan Y, Zhang H, Gao W, Liu D, Endo M, Deshpande GA, Uehara Y, Watanabe D, Yoshikawa S, Mizushima A: Current awareness of palliative care in China. The Lancet Global health 2020, 8(3):e333-e335.

11. Notice on the Implementation of the Hospice Care Project by Shanghai Government in 2012. Available from: http://wsjkw.sh.gov.cn/jcws2/20180815/0012-57262.html. Accessed August 15, 2020.

12. World Health Assembly progress on noncommunicable diseases and traditional medicine. Available from: https://www.who.int/mediacentre/news/releases/2014/WHA-20140523/en/. Accessed August 15, 2020.

13. Basic standards of management and practice of hospice centers. Available from: http://www.nhc.gov.cn/xxgk/pages/viewdocument.jsp? dispatchDate=\&staticUrl=/yzygj/s3593/201702/2f50fdc62fa84cdd9d9a09d5162a661f.shtml\&wenhao=\%E5\%9B\%BD\%E5\%8D\%AB\%E5\%8C\%BB\%E5\%8F 00042\&manuscriptld=2f50fdc62fa84cdd9d9a09d5162a661f. Accessed August 15, 2020.

14. The Second Batch of National Pilot Regions on Hospice Implementation. Available from: http://www.nhc.gov.cn/cmssearch/xxgk/getManuscriptXxgk.htm?id=efe3ed3d9dce4f519bc7bba7997b59d8. Accessed August 15, 2020.

15. Groeneveld El, Higginson IJ: Palliative care as a public health issue. In: Text Book of Palliative Medicine and Supportive Care. edn. Edited by Bruera E, Higginson I, Gunten CFv, Morita T. New York CRC Press; 2015: 79.

16. Bruera E, Hui D: Palliative care research: lessons learned by our team over the last 25 years. Palliative medicine 2013, 27(10):939-951.

17. Chang HT, Lin MH, Chen CK, Hwang SJ, Hwang IH, Chen YC: Hospice palliative care article publications: An analysis of the Web of Science database from 1993 to 2013. Journal of the Chinese Medical Association : JCMA 2016, 79(1):29-33.

18. Liu CJ, Yeh TC, Hsu SH, Chu CM, Liu CK, Chen M, Huang SJ: Bibliometric Analysis of Palliative Care-Related Publication Trends During 2001 to 2016. The American journal of hospice \& palliative care 2018, 35(10):1280-1286.

19. Cheong WL, Mohan D, Warren N, Reidpath DD: Palliative Care Research in the Asia Pacific Region: A Systematic Review and Bibliometric Analysis of PeerReviewed Publications. Journal of palliative medicine 2019, 22(5):545-552.

20. Wang T, Molassiotis A, Chung BPM, Tan JY: Current Research Status of Palliative Care in Mainland China. J Palliat Care 2018, 33(4):215-241.

21. Cai R, Shi F: A reivew on the compilation of A Guide to the Core Journal of China. Journal of Academic Libraries 2002, 20(5):2-5,13.

22. The Asian Pacific Hospice Palliative Care Network. The 7th Singapore Palliative Care Conference Call for Abstracts. Available from: https://singaporepalliativecare.miceapps.com/client/sites/page/497/1306. Accessed April 15, 2020.

23. Chen C: CiteSpace II: Detecting and visualizing emerging trends and transient patterns in scientific literature. Journal of the American Society for Information Science and Technology 2006, 57(3):359-377. 
24. Chen C, Dubin R, Kim MC: Emerging trends and new developments in regenerative medicine: a scientometric update (2000 - 2014). Expert opinion on biological therapy 2014, 14(9):1295-1317.

25. Price DJS: Little Science, Big Science. New York: Columbia University Press; 1963. Cited by: López-Muñoz F, Boya J, Marín F, Calvo JL. Scientific research on the pineal gland and melatonin: a bibliometric study for the period 1966-1994. J Pineal Res 1996;20:115-24.

26. Ning X: Hospice and palliative care research in mainland China: Current status and future direction. Palliative medicine 2019, 33(9):1127-1128.

27. Gu XL, Cheng WW: Chinese oncologists' knowledge, attitudes and practice towards palliative care and end of life issues. Bmc Medical Education 2016, 16.

28. Radbruch L, De Lima L, Knaul F, Wenk R, Ali Z, Bhatnaghar S, Blanchard C, Bruera E, Buitrago R, Burla C et al: Redefining Palliative Care - a New Consensus-based Definition. J Pain Symptom Manage 2020. S0885-3924(20)30247-5. doi:10.1016/j.jpainsymman.2020.04.027

29. Bin P: Dynamic Development of Regional Disparity in Mainland China: An Experimental Study Based on a Multidimensional Index. Sustainability 2016, 8(12):1287.

30. Pastrana T, Vallath N, Mastrojohn J, Namukwaya E, Kumar S, Radbruch L, Clark D: Disparities in the contribution of low- and middle-income countries to palliative care research. J Pain Symptom Manage 2010, 39(1):54-68.

31. Cai JL, Zhao HZ, Coyte PC: Socioeconomic Differences and Trends in the Place of Death among Elderly People in China. International Journal of Environmental Research and Public Health 2017, 14(10).

32. Shi BX, Sun ZS: A Comparative Study of the Understanding of Death between Urban and Rural Christians in North China. Religious Studies 2010(04):108113.

33. Kang L, Liu XH, Zhang J, Shan PY, Wang JP, Zhong P, Du XH, Du YF, Yu BC, Wei N et al: Attitudes Toward Advance Directives Among Patients and Their Family Members in China. Journal of the American Medical Directors Association 2017, 18(9).

34. Yang L, Chen L, Liu HN: The Supply Component and Optimization Path of NIMBY Facilities from the Perspective of Spatial Justice: Study of a Hospice Protest Event in Wuhan. Journal of Huazhong University of Science and Technology (Social Science Edition) 2018, 32(01):125-133.

35. Zhang JJ, Wei YY: The Practice and Dissemination of the Hospice Service of Buddhism: Based on the Case Study of Xuanwu Lake Lama Temple. The World Religious Cultures 2018(01):137-142.

36. Durieux V, Gevenois PA: Bibliometric indicators: quality measurements of scientific publication. Radiology 2010, 255(2):342-351.

\section{Tables}

Table 10Top 10 Journals Publishing HPC-related Articles

\begin{tabular}{|c|c|c|c|c|c|}
\hline \multicolumn{3}{|l|}{ Total Publications } & \multicolumn{3}{|l|}{ High-quality Publications } \\
\hline Number of Publications & & $\%$ & Number of Publications & & $\%$ \\
\hline World Latest Medicine Information & 93 & 2.9 & Chinese general practice ${ }^{1}$ & 46 & 7.2 \\
\hline Chinese Medical Ethics & 83 & 2.6 & Medicine and philosophy ${ }^{1}$ & 33 & 5.2 \\
\hline Electronic Journal of Practical Clinical Nursing Science & 66 & 2.0 & Journal of Pain and Symptom Management ${ }^{2}$ & 31 & 4.9 \\
\hline Chinese Nursing Research ${ }^{1}$ & 60 & 1.9 & Chinese Journal of Gerontology ${ }^{1}$ & 29 & 4.6 \\
\hline Guide of China Medicine & 57 & 1.8 & Chinese Nursing Research ${ }^{1}$ & 27 & 4.2 \\
\hline Electronic Journal of Clinical Medical Literature & 56 & 1.7 & Chinese Journal of Nursing ${ }^{1}$ & 27 & 4.2 \\
\hline Chinese General Practice Nursing & 51 & 1.6 & Chinese Nursing Management ${ }^{1}$ & 20 & 3.1 \\
\hline Shanghai Medical and Pharmaceutical Journal & 51 & 1.6 & Journal of Nursing Science ${ }^{1}$ & 18 & 2.8 \\
\hline Chinese General Practice $^{1}$ & 46 & 1.4 & American Journal of Hospice \& Palliative Medicine ${ }^{2}$ & 14 & 2.2 \\
\hline Journal of Nursing Science ${ }^{1}$ & 39 & 1.2 & Supportive Care in Cancer ${ }^{2}$ & 12 & 1.9 \\
\hline In Total & 602 & 18.7 & In Total & 257 & 40.4 \\
\hline
\end{tabular}

Note: ${ }^{1}$ The Chinese Core Journals; ${ }^{2}$ international Journals in English

Table 2ロRegional indicators of production and impacts 


\begin{tabular}{|c|c|c|c|c|c|c|}
\hline $\begin{array}{l}\text { Province } \\
\text { /Municipal city }\end{array}$ & Total number of publications & $\%$ & Number of publications per million inhabitants & Number of high-quality publications & $\%$ & 5-year RIF of 2019 \\
\hline Beijing & 380 & 11.8 & 17.6 & 108 & 17.0 & 3.9 \\
\hline Shanghai & 358 & 11.1 & 14.8 & 103 & 16.2 & 2.8 \\
\hline Jiangsu & 263 & 8.2 & 3.3 & 39 & 6.1 & 2.4 \\
\hline Guangdong & 234 & 7.3 & 2.1 & 41 & 6.4 & 3.1 \\
\hline Sichuan & 172 & 5.3 & 2.1 & 39 & 6.1 & 4.0 \\
\hline Hubei & 169 & 5.2 & 2.9 & 45 & 7.1 & 1.7 \\
\hline Shandong & 165 & 5.1 & 1.6 & 32 & 5.0 & 8.5 \\
\hline Zhejiang & 157 & 4.9 & 2.7 & 24 & 3.8 & 4.6 \\
\hline Henan & 155 & 4.8 & 1.6 & 24 & 3.8 & 2.4 \\
\hline Jilin & 117 & 3.6 & 4.3 & 11 & 1.7 & 5.3 \\
\hline Liaoning & 107 & 3.3 & 2.5 & 12 & 1.9 & 11.0 \\
\hline Hebei & 98 & 3.0 & 1.3 & 12 & 1.9 & 3.6 \\
\hline Tianjin & 86 & 2.7 & 5.5 & 31 & 4.9 & 5.1 \\
\hline Shanxi & 85 & 2.6 & 2.3 & 9 & 1.4 & 2 \\
\hline Anhui & 81 & 2.5 & 1.3 & 6 & 0.9 & 1.5 \\
\hline Chongqing & 69 & 2.1 & 2.2 & 21 & 3.3 & 1.8 \\
\hline Hunan & 63 & 2.0 & 0.9 & 17 & 2.7 & 5.9 \\
\hline Shaanxi & 58 & 1.8 & 1.5 & 7 & 1.1 & 1.8 \\
\hline Fujian & 54 & 1.7 & 1.4 & 9 & 1.4 & 4.4 \\
\hline Heilongjiang & 51 & 1.6 & 1.4 & 8 & 1.3 & 2.8 \\
\hline Yunnan & 46 & 1.4 & 1.0 & 5 & 0.8 & 1 \\
\hline Xinjiang & 44 & 1.4 & 1.8 & 2 & 0.3 & 1 \\
\hline Guizhou & 43 & 1.3 & 1.2 & 8 & 1.3 & 4.8 \\
\hline Guangxi & 42 & 1.3 & 0.9 & 7 & 1.1 & 1 \\
\hline Inner Mongolia & 34 & 1.1 & 1.3 & 1 & 0.2 & 0 \\
\hline Jiangxi & 24 & 0.7 & 0.5 & 2 & 0.3 & 4 \\
\hline Gansu & 23 & 0.7 & 0.9 & 5 & 0.8 & 0.7 \\
\hline Qinghai & 21 & 0.7 & 3.5 & 2 & 0.3 & 3 \\
\hline Ningxia & 16 & 0.5 & 2.3 & 4 & 0.6 & 1.7 \\
\hline Hainan & 9 & 0.3 & 1.0 & 1 & 0.2 & 0 \\
\hline Tibet & 0 & 0.0 & 0.0 & 0 & 0.0 & $\mathrm{~N} / \mathrm{A}$ \\
\hline
\end{tabular}

Table 3: Themes in high-quality publications

\begin{tabular}{lcc}
\hline Theme & Number of publications & $\%$ \\
\hline HPC in Cancer patients & 250 & 39.3 \\
Pain and symptom management & 136 & 21.4 \\
\hline Assessment of needs and implementation of HPC & 95 & 14.9 \\
\hline Policy and program advocacy & 68 & 10.7 \\
\hline Spiritual and psychological care & 56 & 8.8 \\
\hline Nursing in HPC & 54 & 8.5 \\
\hline Humanity and art & 44 & 6.9 \\
\hline Education and training & 43 & 6.8 \\
\hline HPC in non-cancer patients & 38 & 6.0 \\
\hline HPC in primary care & 37 & 5.8 \\
\hline Aging and geriatric HPC & 37 & 5.8 \\
\hline Communication and advanced care planning & 36 & 5.7 \\
\hline Complementary therapy & 34 & 5.3 \\
\hline Ethics & 28 & 4.4 \\
\hline Family care givers and volunteers & 27 & 4.2 \\
\hline HPC in other specialties & 13 & 2.0 \\
\hline Pedia tric HPC & 12 & 1.9 \\
\hline Self-care of the HPC team & 8 & 1.3 \\
\hline Rehabilitation and nutrition & 7 & 1.1 \\
\hline HPC screening and timing & 6 & 0.9 \\
\hline Bereavement & 4 & 0.6 \\
\hline
\end{tabular}

Figures 
Records identified through database searching (WoS, Scopus, PubMed, CINAHL, OVID, CNKI)

Titles, abstracts, and author affiliations reviewed

Duplicates removal

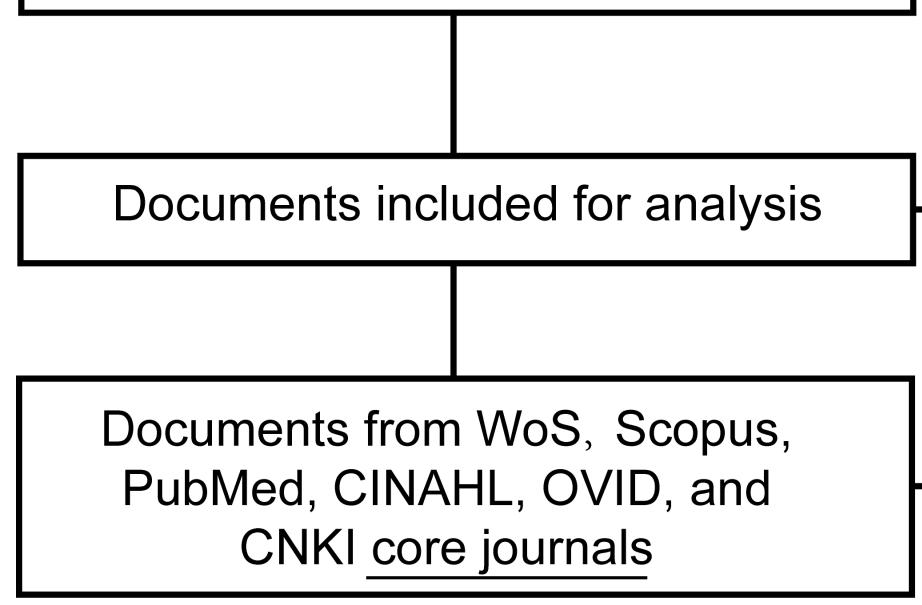

English articles focusing on places outside Mainland China excluded

Curative medicine or other irrelevant topics excluded

Chinese translation of work from an international journal in English excluded

Figure 1

Flow chart of the bibliometric study

High-quality publications:

Citation records retrieval and

theme categorization

\section{Total publications}




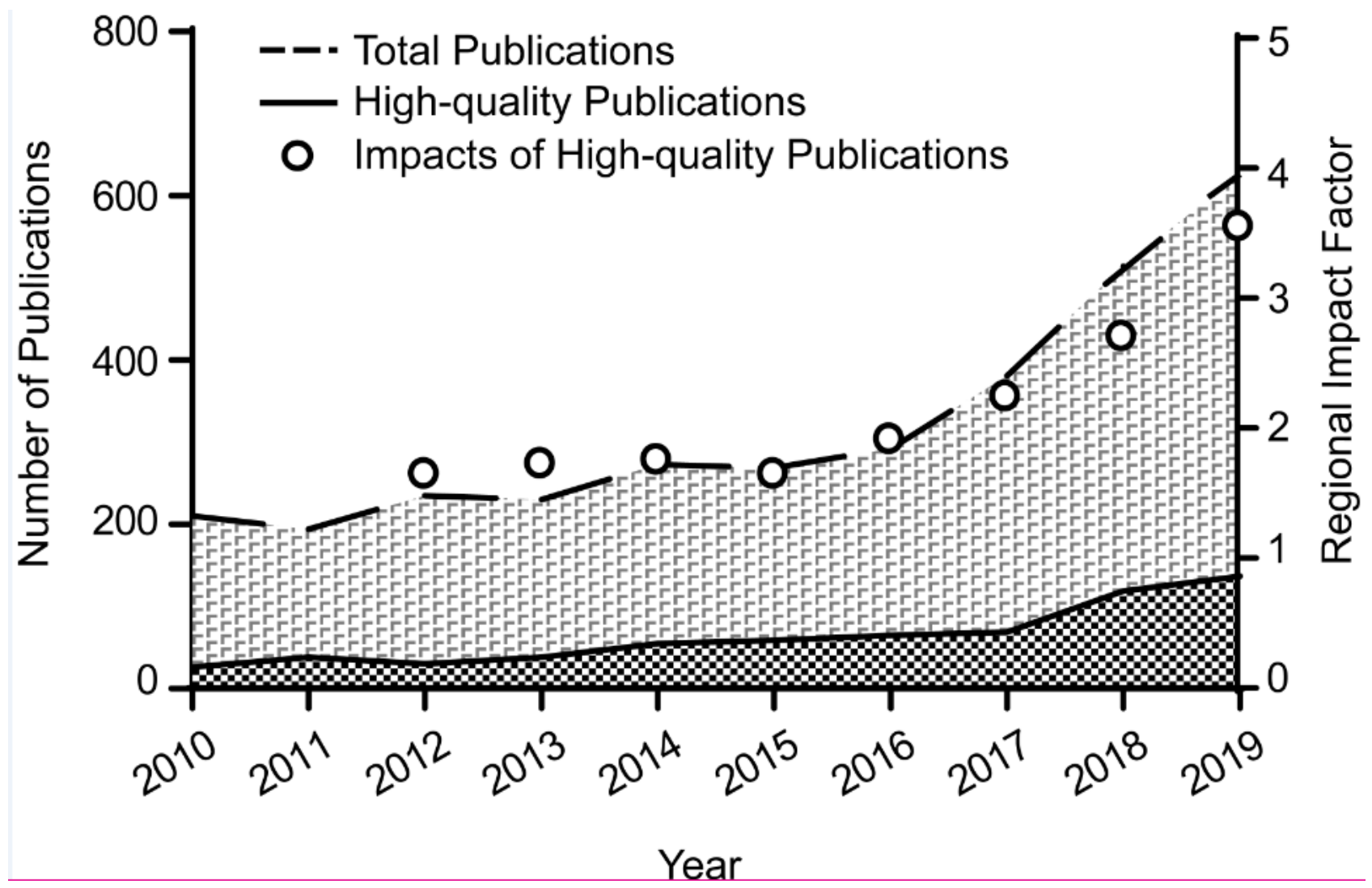

Figure 2

Annual development of production and impacts of publications
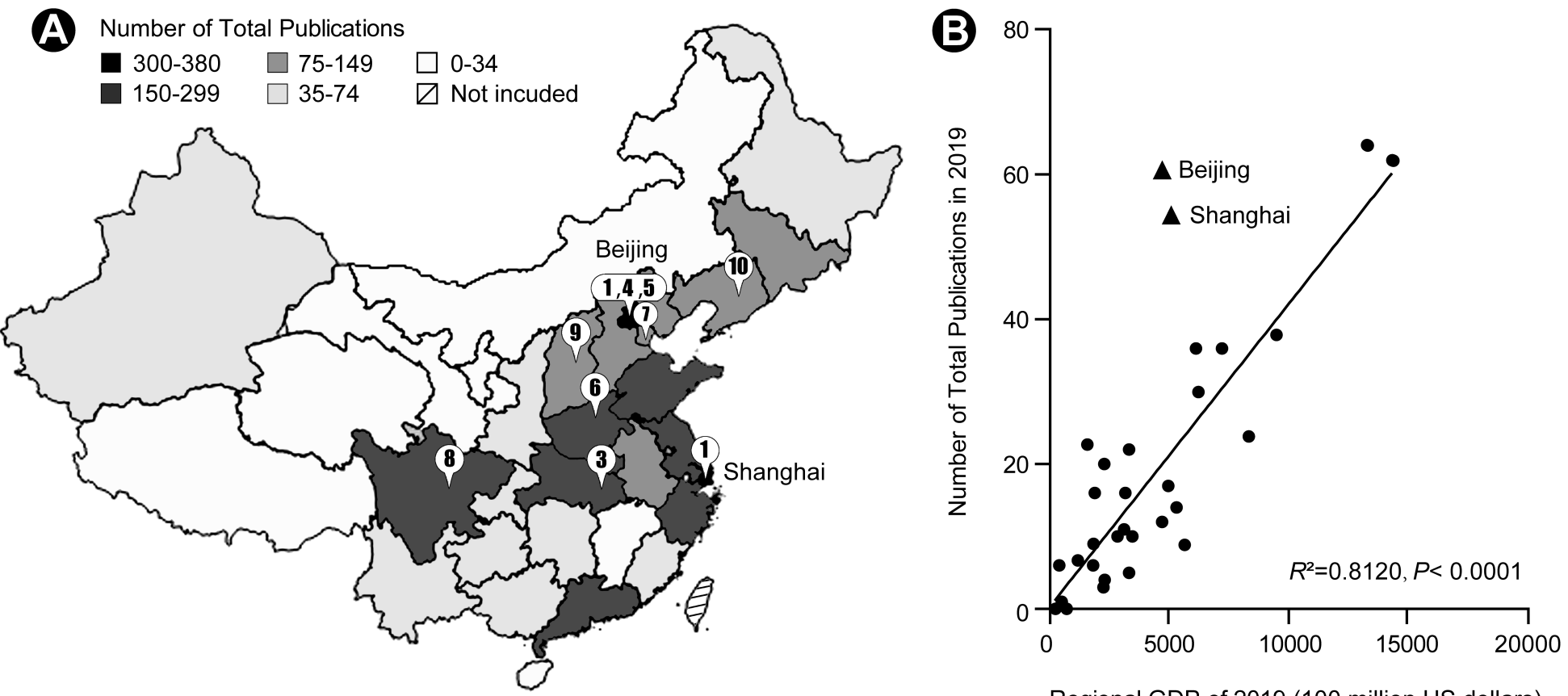

Regional GDP of 2019 (100 million US dollars)

(1) Peking University \& Fudan University (equal first) (3) Huazhong University of Science and Technology (4) Capital Medical University
(5) Peking Union Medical College
(6) Zhengzhou University
(7) Tianjin Medical University
(8) Sichuan University
(9) Shanxi Medical University
(10) China Medical University

Figure 3

Regional distribution of publications Note: A, A heatmap of regional production, and locations and ranks of the top-10 productive institutes; B, an example of the correlation between annual regional GDP and number of publications in 2019. The GDP was based on a currency exchange rate of 689.85 Chinese Yuan 
to 100 United States dollar in 2019. Beijing and Shanghai were excluded from the regression model as outliers. The heatmap was generated by Microsoft Excel. The map was adapted from Bing@GeoNames, HERE, MSFT, Microsoft, NavInfo, Wikipedia with permission from Microsoft Corporation. Note: The designations employed and the presentation of the material on this map do not imply the expression of any opinion whatsoever on the part of Research Square concerning the legal status of any country, territory, city or area or of its authorities, or concerning the delimitation of its frontiers or boundaries. This map has been provided by the authors.

Key Words

HPC 1

Community health care

Severity of illness index ${ }^{2}$

Validity 2

Advanced gastric cancer

Gastric cancer

Perspective 2

Family member

Chinese patient 2

Quality nursing care

Risk factor 2

Medical staff

Negetive emotions

Pain management
Strength Begin End

$\begin{array}{lll}13.0542 & 2015 \quad 2017\end{array}$

$\begin{array}{lll}11.3629 & 2015 & 2017\end{array}$

$2.6865 \quad 2015 \quad 2017$

3.968

2015

2016

3.7806

2015

2016

$3.2397 \quad 2015 \quad 2016$

$2.9142 \quad 2015 \quad 2016$

$2.5715 \quad 2015 \quad 2016$

$\begin{array}{lll}2.6981 & 2015 & 2017\end{array}$

$\begin{array}{lll}4.5162 & 2016 & 2017\end{array}$

$\begin{array}{lll}2.7974 & 2016 & 2017\end{array}$

$\begin{array}{lll}4.1786 & 2016 \quad 2017\end{array}$

$3.1845 \quad 2016 \quad 2019$

$\begin{array}{lll}5.328 & 2017 \quad 2019\end{array}$
2010-2019
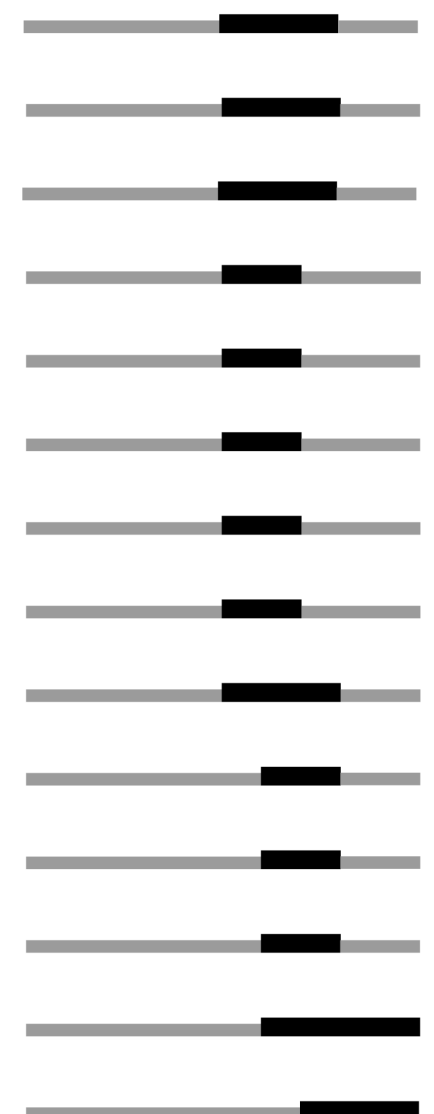

Figure 4

Key words and burst periods from 2015 Note: 1 One Chinese version of HPC (shu-huan-liao-hu); 2 original terms in English-language articles not translated Supplementary Files

This is a list of supplementary files associated with this preprint. Click to download.

- AdditionalFile.docx

- AdditionalFile.docx 